\title{
Perfil físico-químico do soro de queijos mozarela e minas-padrão produzidos em várias regiões do estado de Minas Gerais
}

\author{
[Physical-chemical profile of the whey of minas-padrão and mozzarella cheeses produced \\ in some regions of Minas Gerais state] \\ L.V. Teixeira, L.M. Fonseca* \\ Escola de Veterinária - UFMG \\ Caixa Postal 567 \\ 30123-970 - Belo Horizonte, MG
}

\begin{abstract}
RESUMO
O perfil físico-químico de soros de queijos mozarela e minas-padrão foi analisado em quatro das cinco macrorregiões com maior produção desses queijos no estado de Minas Gerais: Alto São Francisco, Zona Metalúrgica, Zona da Mata e Sul de Minas. Os valores média+desvio padrão encontrados para os componentes do soro de queijo mozarela foram: $-0,565 \pm 0,031^{\circ} \mathrm{H}$ para crioscopia; $6,19+0,26 \mathrm{para} \mathrm{pH}$; $13,16+3,08^{\circ} \mathrm{D}$ para acidez; $6,33 \pm 0,43 \mathrm{~g} / 100 \mathrm{~g}$ para sólidos totais; $93,67 \pm 0,43 \mathrm{~g} / 100 \mathrm{~g}$ para umidade; $0,77 \pm 0,26 \mathrm{~g} / 100 \mathrm{~g}$ para gordura; $0,84 \pm 0,04 \mathrm{~g} / 100 \mathrm{~g}$ para proteína; 4,42 $\pm 0,68 \mathrm{~g} / 100 \mathrm{~g}$ para lactose; $0,47 \pm 0,04 \mathrm{~g} / 100 \mathrm{~g}$ para cinzas; $0,18 \pm 0,01 \mathrm{~g} / 100 \mathrm{~g}$ para cloretos e $1,0253 \pm 0,0006$ para densidade. Para soro

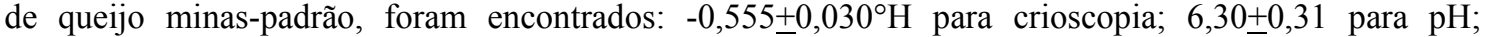
$12,48+2,07^{\circ} \mathrm{D}$ para acidez; $6,28+0,51 \mathrm{~g} / 100 \mathrm{~g}$ para sólidos totais; $93,97 \pm 0,54 \mathrm{~g} / 100 \mathrm{~g}$ para umidade; $0,70+0,21 \mathrm{~g} / 100 \mathrm{~g}$ para gordura; $0,49 \pm 0,03 \mathrm{~g} / 100 \mathrm{~g}$ para cinzas; 4,12+0,36 g/100g para lactose; $0,80 \pm 0,04 \mathrm{~g} / 100 \mathrm{~g}$ para proteínas; $0,20 \pm 0,01 \mathrm{~g} / 100 \mathrm{~g}$ para cloretos e $1,0249 \pm 0,0009$ para densidade. Não houve diferença significativa entre os dois tipos de soro, mas encontrou-se diferença entre os soros de diferentes regiões para crioscopia, sólidos totais, umidade e densidade, e observou-se interação tipo de soro versus região para proteínas, acidez, gordura e cloretos. Os teores de lactose e resíduo mineral fixo (cinzas) não apresentaram nenhuma diferença significativa. Por não existir um padrão de identidade e qualidade específico para soros de queijo, esses resultados podem ser tomados como base para se desenvolver tais padrões.
\end{abstract}

Palavras-chave: soro de queijo, mozarela, minas-padrão, perfil físico-químico, Minas Gerais

\begin{abstract}
The physical-chemical profile of the whey of mozzarella and minas-padrão cheeses was studied in four regions ("Alto São Francisco", "Zona Metalúrgica", "Zona da Mata" and "Sul de Minas") which produce milk and cheese in Minas Gerais. Due to the lack of a specific identity and a quality pattern for cheese whey, the results can be taken as a base to develop such patterns. The mean values found for mozzarella cheese whey were: - $0.565 \pm 0.031^{\circ} \mathrm{H}$ for freezing point; $6.19 \pm 0.26$ for $\mathrm{pH} ; 13.16 \pm 3.08^{\circ} \mathrm{D}$ for titratable acidity; $6.33 \pm 0.43 \mathrm{~g} / 100 \mathrm{~g}$ for total solids; $93.67 \pm 0.43 \mathrm{~g} / 100 \mathrm{~g}$ for moisture; $0.77 \pm 0.26 \mathrm{~g} / 100 \mathrm{~g}$ for fat; $0.84 \pm 0.04 \mathrm{~g} / 100 \mathrm{~g}$ for protein; $4.42 \pm 0.68 \mathrm{~g} / 100 \mathrm{~g}$ for lactose; $0.47 \pm 0.04 \mathrm{~g} / 100 \mathrm{~g}$ for ashes; $0.18 \pm 0.01 \mathrm{~g} / 100 \mathrm{~g}$ for chlorine and $1.0253 \pm 0.0006$ for density. In relation to minas-padrão cheese whey, the following mean results were obtained: - $0.555 \pm 0.030^{\circ} \mathrm{H}$ for freezing point; $6.30 \pm 0.31$ for $\mathrm{pH}$; $12.48 \pm 2.07^{\circ} \mathrm{D}$ for titratable acidity; $6.28 \pm 0.51 \mathrm{~g} / 100 \mathrm{~g}$ for total solids; $93.97 \pm 0.54 \mathrm{~g} / 100 \mathrm{~g}$ for moisture; $0.70 \pm 0.21 \mathrm{~g} / 100 \mathrm{~g}$ for fat; $0.80 \pm 0.04 \mathrm{~g} / 100 \mathrm{~g}$ for protein; $4.12 \pm 0.36 \mathrm{~g} / 100 \mathrm{~g}$ for lactose; $0.49 \pm 0.03 \mathrm{~g} / 100 \mathrm{~g}$ for ashes; $0.20 \pm 0.01 \mathrm{~g} / 100 \mathrm{~g}$ for chlorine and $1.0249 \pm 0.0009$ for density. No statistical difference between those types of whey was observed, but difference among wheys from regions for freezing point, total
\end{abstract}

Recebido em 25 de abril de 2007

Aceito em 19 de dezembro de 2007

*Autor para correspondência (corresponding author)

E-mail:leorges@vet.ufmg.br 
solids, moisture and density as well as interaction whey $x$ regions for protein, titratable acidity, fat, and chorine were found. Only lactose and ash contents did not present any statistical difference.

Keywords: cheese whey, mozzarella cheese, minas-padrão cheese, physical and chemical profile; Minas Gerais.

\section{INTRODUÇ̃̃O}

As principais regiões mineiras produtoras de leite estão centralizadas nas mesorregiões do Triângulo Mineiro, Alto Paranaíba, Sul e Sudeste, que juntas correspondem a mais de dois bilhões de litros de leite por ano (Martins, 2001).

A indústria queijeira representa um importante segmento do setor lácteo, com a produção nacional sob inspeção federal totalizando cerca de 423.000 toneladas em 2002 (Spilotro, 2003). No ano de 2004, pela primeira vez no Brasil, obteve-se superavit na balança comercial do mercado do leite, 51 milhões de dólares em novembro (Jardim, 2004), o que mostra um mercado produtor em plena expansão. Minas Gerais é o maior produtor de queijos do Brasil, 215 mil toneladas por ano, o que equivale a $50 \%$ da produção nacional. Essa indústria fatura 5,5 bilhões de reais, apresentando crescimento médio de $10 \%$ ao ano. A tendência é de aumentar esses números devido ao crescente aumento no consumo de lácteos, principalmente de queijos, que está na ordem de 2,3 quilos per capita ao ano (Martins, 2001). Essa tendência se confirma com o que foi registrado em 2004 na balança comercial de lácteos de Minas Gerais. Somente em novembro, as exportações dos produtos somaram 12,7 milhões de dólares, contra 6,6 milhões de dólares em importações (Minas..., 2005).

Dentre os queijos mais produzidos no Brasil, está o queijo minas e suas variedades mais importantes, minas frescal e minas-padrão. Em Minas Gerais, os queijos mais produzidos são, em ordem, a mozarela, o queijo minas (padrão e frescal) e o requeijão, correspondendo, respectivamente, a $24 \%, 21 \%$ e $14,5 \%$ do total da produção. A maior parte dos laticínios do estado está concentrada nas regiões Sul (36,5\%), Zona da Mata (17\%), Triângulo Mineiro e Alto Paranaíba (14,8\%) e Metalúrgica (14,4\%) (Martins, 2001).

O soro lácteo pode ser definido como a fração aquosa do leite que é separada da caseína durante a produção de queijos, correspondendo a cerca de $90 \%$ do volume do leite, dependendo do tipo de queijo processado (Furtado e Lourenço Neto, 1994; Camargo et al., 2000). Os sólidos do soro representam 50 a $55 \%$ dos sólidos totais do leite. De modo geral, o soro é rico em proteínas, lactose, minerais e vitaminas (Kosikowski, 1979; Duarte e Mídio, 1997).

A composição e o tipo de soro produzido na indústria leiteira variam em função dos processos tecnológicos empregados, do leite utilizado e do tipo de queijo fabricado (Furtado e Pombo, 1979; Marwaha e Kennedy, 1988). Os principais tipos de soro são o obtido por coagulação enzimática, definido como soro doce, e o obtido por coagulação ácida, o soro ácido (Kosikowski, 1979).

Várias opções para o aproveitamento do soro podem ser utilizadas, desde o uso como matériaprima na elaboração de bebidas lácteas, até a utilização de modernas tecnologias para obtenção de produtos específicos e/ou novos a serem utilizados principalmente pelas indústrias alimentícias (Coton, 1985; Chiappini et al., 1995; Ferreira, 1997). Contudo, para o aproveitamento racional do soro, faz-se necessária a determinação do seu perfil de qualidade microbiológica e físico-química, que indicará quais processamentos serão mais adequados e quais produtos podem resultar dessa matériaprima (Ferreira, 1997; Fonseca, 1999).

Este trabalho teve por objetivos determinar a composição e a qualidade físico-química dos soros de queijos mozarela e minas-padrão produzidos em regiões do estado de Minas Gerais e procurar estabelecer critérios e parâmetros para a inspeção higiênico-sanitária do soro de queijo.

\section{MATERIAL E MÉTODOS}

As amostras foram coletadas em duas cidades diferentes de cada uma das quatro macrorregiões, Alto São Francisco, Metalúrgica, Zona da Mata e Sul de Minas, em laticínios de médio ou grande 
porte ou cooperativas, com registro na Inspeção Federal, perfazendo um total de 24 amostras. Estas foram coletadas diretamente do tanque de produção, logo após o corte da massa, em recipiente plástico esterilizado, acondicionado com gelo reciclável e transportado em caixas isotérmicas. O início das análises ocorreu em um prazo máximo de um dia após a coleta do soro, realizadas durante o período de outubro de 2002 a março de 2003, relativo ao período chuvoso da região Sudeste.

Os componentes pesquisados foram: proteínas, pelo método macro-Kjeldhahl (Determination..., 1993); gordura, pelo método Roese-Gottlieb, descrito para soro de queijo (Official..., 1995); resíduo mineral fixo (Official..., 1995); umidade e sólidos totais (Determination..., 1987); cloreto de sódio, pelo método argentométrico; acidez titulável, em graus Dornic; densidade relativa; índice crioscópico e $\mathrm{pH}$. Para os cinco últimos citados, usou-se a metodologia divulgada pelo Ministério da Agricultura, Pecuária e Abastecimento (Métodos..., 2003), para leite ou produtos lácteos, visto não haver técnicas específicas para soro. $\mathrm{O}$ teor de lactose foi obtido por meio da diferença entre sólidos totais e a soma dos teores de gordura, cinzas e proteína total. Todas as análises foram realizadas em duplicata.
Empregou-se o delineamento inteiramente ao acaso, com fatorial $2 \times 4$ (tipo de soro x região), com seis repetições (Sampaio, 2002). Os resultados físico-químicos foram analisados pela comparação de médias, por meio dos testes Duncan, quando o coeficiente de variação $(\mathrm{CV})$ apresentou-se entre 15 e $35 \%$, ou StudentNewman e Keuls, quando o CV apresentou-se abaixo de $15 \%(\mathrm{P}<0,05)$. Para tais cálculos, foi empregado o programa SAEG $^{\circledR}$ (Euclides, 2001).

\section{RESULTADOS E DISCUSSÃO}

A existência de interação significativa de região versus tipo de soro para $\mathrm{pH}$, acidez e teores de gordura, proteína e cloreto de sódio foi significativa (Tab. 1). Para crioscopia, densidade relativa, sólidos totais e umidade, a diferença significativa foi apenas entre regiões, sem qualquer interação. Apenas os teores de cinzas e de lactose não diferiram entre regiões. Não houve diferença entre tipos de soro, o que facilita a inspeção, uma vez que o soro oriundo de vários tipos de queijos chega ao local de beneficiamento já misturado. A diferença entre regiões pode ter diversas causas que, provavelmente, estão ligadas à qualidade da matéria-prima e do processamento, além de características peculiares de cada região e rebanho, como umidade e temperatura médias.

Tabela 1. Resultados físico-químicos de soro de queijos mozarela e minas-padrão no estado de Minas Gerais

\begin{tabular}{l|c|c|c|c}
\hline \multirow{2}{*}{} & \multicolumn{2}{|c|}{ Soro de queijo mozarela } & \multicolumn{2}{c}{ Soro de queijo minas-padrão } \\
\cline { 2 - 4 } & Média & $\begin{array}{c}\text { Coeficiente de } \\
\text { variação }(\% \mathrm{CV})\end{array}$ & Média & $\begin{array}{c}\text { Coeficiente de } \\
\text { variação }(\% \mathrm{CV})\end{array}$ \\
\hline Crioscopia ${ }^{\circ} \mathrm{H}$ & $-0,565$ & 5,5 & $-0,555$ & 5,5 \\
$\mathrm{pH}$ & 6,19 & 4,3 & 6,3 & 4,9 \\
Acidez ${ }^{\circ} \mathrm{D}$ & 13,17 & 23,4 & 12,49 & 16,8 \\
Sol. totais $(\mathrm{g} / 100 \mathrm{~g})$ & 6,33 & 6,7 & 6,28 & 8,1 \\
Umidade $(\mathrm{g} / 100 \mathrm{~g})$ & 93,67 & 0,4 & 93,72 & 0,6 \\
Gordura $(\mathrm{g} / 100 \mathrm{~g})$ & 0,77 & 33,9 & 0,68 & 31,7 \\
Proteínas $(\mathrm{g} / 100 \mathrm{~g})$ & 0,84 & 4,8 & 0,80 & 4,9 \\
Cinzas $(\mathrm{g} / 100 \mathrm{~g})$ & 0,47 & 8,3 & 0,49 & 5,6 \\
Cloretos $(\mathrm{g} / 100 \mathrm{~g})$ & 0,18 & 8,1 & 0,19 & 5,7 \\
Lactose $(\mathrm{g} / 100 \mathrm{~g})$ & 4,42 & 15,0 & 4,12 & 9,0 \\
Densidade & 1,0253 & 0,06 & 1,0249 & 0,09 \\
\hline
\end{tabular}

A média geral_desvio-padrão para umidade dos soros (Tab. 2) foi de 93,81 $\pm 0,64 \mathrm{~g} / 100 \mathrm{~g}$ com CV de $0,52 \%$. Estes valores assemelham-se aos encontrados na literatura (Kosikowski e Mistry, 1997; Chiappini e Santos, 1995 e Siqueira, 2000), demonstrando que a maioria dos grandes laticínios segue um processamento padrão, obtendo, assim, um produto (tanto o queijo, quanto o soro) com uma faixa de variação constante de suas composições. Houve diferença significativa entre as médias das regiões, sendo o soro da região da Zona da Mata diferente do soro 
das Zonas Metalúrgica e Alto São Francisco, com maior umidade $(\mathrm{P}<0,05)$.

Os valores encontrados para sólidos totais (Tab. 2) dos soros apresentaram-se na faixa de 5,35 a $7,08 \mathrm{~g} / 100 \mathrm{~g}$, com média de $6,31 \mathrm{~g} / 100 \mathrm{~g}$, desviopadrão de 0,66 e $\mathrm{CV}=7,4 \%$, valores semelhantes aos encontrados por Bylund (1975), Wolfschoon e Furtado (1977) e Sbampato et al. (1998). A porcentagem de sólidos totais apresentou diferença significativa somente entre regiões. Apenas as amostras de soro provenientes das regiões do Sul de Minas e do Alto São Francisco não apresentaram diferença significativa entre si, contudo ambas diferenciaram-se das outras duas regiões, que também foram diferentes entre si (Tab. 2). A diferença observada na Zona da Mata para umidade e sólidos totais em relação às demais regiões deve-se, provavelmente, ao processamento da mozarela aplicado pelo laticínio, onde era feita uma lavagem da massa com água durante a dessora. Esse tipo de diferenciação no processamento interfere na composição do soro, o que dificultaria, por exemplo, uma inspeção desse produto. Os teores de sólidos totais e umidade foram os componentes que apresentaram os menores coeficientes de variação, juntamente com a densidade. $\mathrm{O}$ teor de umidade está diretamente relacionado ao teor de sólidos totais, em proporção inversa, como foi observado.

Tabela 2. Teores de umidade $(\mathrm{g} / 100 \mathrm{~g})$ dos soros de mozarela e minas-padrão das macrorregiões do Sul de Minas (SM), Alto São Francisco (ASF), Zona da Mata (ZM) e Zona Metalúrgica (MT)

\begin{tabular}{ccc}
\hline Região & $\begin{array}{c}\text { Umidade } \\
(\mathrm{g} / 100 \mathrm{~g})\end{array}$ & $\begin{array}{c}\text { Sólidos totais } \\
(\mathrm{g} / 100 \mathrm{~g})\end{array}$ \\
\hline ZM & $94,40 \mathrm{a}$ & $5,60 \mathrm{a}$ \\
SM & $93,94 \mathrm{ab}$ & $6,06 \mathrm{ab}$ \\
ASF & $93,50 \mathrm{~b}$ & $6,50 \mathrm{~b}$ \\
MT & $93,45 \mathrm{~b}$ & $6,55 \mathrm{~b}$ \\
\hline
\end{tabular}

*Letras distintas na coluna indicam valores diferentes pelo teste SNK $(\mathrm{P}<0,05)$.

Os valores encontrados para índice crioscópico dos soros (Tab. 3) apresentaram-se com média geral de $-0,560^{\circ} \mathrm{H}$, desvio-padrão de $-0,045$ e CV de $5,5 \%$, diferindo dos valores encontrados por Siqueira (2000), que foram de $-0,513^{\circ} \mathrm{H}$ para soro de queijo minas-padrão e $-0,480^{\circ} \mathrm{H}$ para soro de queijo mozarela, ainda que tenham sido utilizados a mesma metodologia e o mesmo equipamento. Mas, semelhante ao encontrado por Siqueira (2000), não houve diferença significativa entre os dois tipos de soros. A crioscopia apresentou diferença significativa $(\mathrm{P}<0,05)$ somente entre as amostras de soro da região Zona da Mata em relação às demais. Essa diferença provavelmente é devido ao fato de o principal laticínio dessa região lavar a massa durante a dessora, o que incorporaria água ao soro. Os valores de crioscopia estão diretamente associados aos teores de lactose e cloretos, que controlam a osmolaridade do leite no úbere em relação à pressão osmótica do sangue, sendo que os valores encontrados tanto para crioscopia quanto para os outros constituintes dos soros apresentam-se coerentes. Contudo, é importante ressaltar que existem poucos trabalhos referindose ao ponto crioscópico do soro.

Tabela 3. Crioscopia $\left({ }^{\circ} \mathrm{H}\right)$ de soros de queijos mozarela e minas-padrão das macrorregiões do Sul de Minas (SM), Alto São Francisco (ASF), Zona da Mata (ZM) e Zona Metalúrgica (MT)

\begin{tabular}{cc}
\multicolumn{2}{c}{ Índice crioscópico } \\
\hline Região & Média $\left({ }^{\circ} \mathrm{H}\right)$ \\
\hline MT & $-0,5922 \mathrm{a}$ \\
ASF & $-0,5713 \mathrm{a}$ \\
SM & $-0,5680 \mathrm{a}$ \\
ZM & $-0,5084 \mathrm{~b}$ \\
\hline
\end{tabular}

*Letras distintas indicam valores diferentes pelo teste SNK $(\mathrm{P}<0,01)$.

Em relação ao potencial hidrogeniônico $(\mathrm{pH})$, os soros apresentaram média para soro de queijode-minas de 6,30 (CV $=0,049)$ e para soro de queijo tipo mozarela de $6,19(\mathrm{CV}=0,043)$. A média $\_$desvio-padrão geral para os dois tipos de soro foi de 6,25+0,371 com CV de 4,6\%. Esses valores assemelham-se aos encontrados por Morr (1990), Chiappini e Santos (1995) e Maciel et al. (1999), que variaram entre 5,0 e 6,6, com maior concentração de valores entre 6,0 e 6,5 . Houve interação soro $\mathrm{x}$ região. Somente na região Metalúrgica e no soro de mozarela houve queda significativa do $\mathrm{pH}$ (Tab. 4).

A interação soro $\mathrm{x}$ região mostra que o tipo de soro só manifesta diferença estatística dependendo da região. Isto provavelmente reflete a influência da qualidade da matéria-prima e do processamento utilizado em cada tipo de queijo, como a diferença de fermento entre mozarela e 
minas-padrão, a acidez do leite destinado à produção dos queijos, entre outros.

Tabela 4. Potencial hidrogeniônico $(\mathrm{pH})$ de soros de queijos mozarela e minas-padrão das macrorregiões do Sul de Minas (SM), Alto São Francisco (ASF), Zona da Mata (ZM) e Zona Metalúrgica (MT)

\begin{tabular}{ccc}
\hline \multirow{2}{*}{ Região } & \multicolumn{2}{c}{$\mathrm{pH}$} \\
\cline { 2 - 3 } & Mozarela & M. padrão \\
\hline ASF & $6,12 \mathrm{a} \mathrm{A}$ & $6,33 \mathrm{a} \mathrm{A}$ \\
MT & $5,66 \mathrm{~b} \mathrm{~B}$ & $6,47 \mathrm{a} \mathrm{A}$ \\
ZM & $6,57 \mathrm{a} A$ & $6,36 \mathrm{a} \mathrm{A}$ \\
SM & $6,41 \mathrm{a} \mathrm{A}$ & $6,05 \mathrm{a} \mathrm{A}$ \\
\hline
\end{tabular}

*Na linha, médias com letras maiúsculas distintas diferem entre si pelo teste SNK $(\mathrm{P}<0,01)$.

* Na coluna, médias com letras minúsculas distintas diferem entre si pelo teste SNK $(\mathrm{P}<0,01)$.

Para os teores de acidez titulável (Tab. 5), os valores concentraram-se, para ambos os soros, entre $9,07^{\circ} \mathrm{D}$ e $14,00^{\circ} \mathrm{D}$. Apenas uma amostra de cada tipo de soro apresentou valor muito alto, elevando a média das respectivas regiões. A média geral foi igual a $12,73^{\circ} \mathrm{D}$, com desviopadrão de $3,66^{\circ} \mathrm{D}$ e alto $\mathrm{CV}, 20,3 \%$. Mesmo com essa alta variação, os resultados encontrados estão coerentes com os apresentados na literatura consultada (Chiappini e Santos, 1995; Kosikowski e Mistry, 1997; Siqueira, 2000).

Tabela 5. Acidez $\left({ }^{\circ} \mathrm{D}\right)$ de soros de queijos mozarela e minas-padrão das macrorregiões do Sul de Minas (SM), Alto São Francisco (ASF), Zona da Mata (ZM) e Zona Metalúrgica (MT)

\begin{tabular}{ccc}
\hline \multirow{2}{*}{ Região } & \multicolumn{2}{c}{ Acidez } \\
\cline { 2 - 3 } & Mozarela & M. padrão \\
\hline ASF & $13,23 \mathrm{aB}$ & $12,47 \mathrm{aB}$ \\
MT & $17,55 \mathrm{aA}$ & $10,52 \mathrm{bB}$ \\
ZM & $9,39 \mathrm{aB}$ & $9,98 \mathrm{aBA}$ \\
SM & $12,50 \mathrm{bB}$ & $16,96 \mathrm{aA}$
\end{tabular}

*Na linha, médias com letras maiúsculas distintas diferem entre si pelo teste Duncan $(\mathrm{P}<0,01)$.

*Na coluna, médias com letras minúsculas distintas diferem entre si pelo teste Duncan $(\mathrm{P}<0,01)$.

Foi observada interação significativa soro $\mathrm{x}$ região $\quad(\mathrm{P}<0,01)$. A região Metalúrgica apresentou maior média de acidez titulável para soro de mozarela, e a região Sul de Minas para o soro de minas-padrão (Tab. 5). Esses valores encontrados para acidez apresentaram uma relação diretamente proporcional aos valores para contagem de coliformes, realizada em trabalho paralelo (Teixeira et al., 2007), ou seja, quanto maior a contagem bacteriana maior acidez do soro. Isto se deve ao fato de o principal produto metabólico bacteriano ser o ácido lático proveniente da metabolização da lactose pela bactéria.

O teor de gordura foi o que apresentou maior diferença entre os dados pesquisados em relação a outros autores e, conseqüentemente, apresentou interação entre soro e região. Enquanto a grande maioria dos trabalhos encontrou resultados de gordura no soro em torno de $0,5 \mathrm{~g} / 100 \mathrm{~g}$ e altos coeficientes de variação, neste experimento os valores foram média de $0,72+0,27 \mathrm{~g} / 100 \mathrm{~g}$ e $\mathrm{CV}=$ $32,9 \%$. Essa variação pode ser explicada por ser a gordura o componente mais variável na constituição do leite, sendo o teor de gordura diretamente influenciado pela padronização do leite utilizado como matéria-prima para produção do queijo, pelo rendimento do queijo e pelo próprio processamento, o que não foi avaliado neste trabalho. Houve interação região versus tipo de soro, principalmente para o soro de mozarela na região Sul de Minas. A porcentagem de gordura no soro foi diferente $(\mathrm{P}<0,05)$ entre regiões, sendo que a região Zona da Mata apresentou a menor média para o soro de mozarela e a região Sul de Minas a menor média para o soro de minas-padrão e a maior para o soro de mozarela (Tab. 6).

Tabela 6. Teores de gordura $(\mathrm{g} / 100 \mathrm{~g})$ de soros de queijos mozarela e minas-padrão, das macrorregiões do Sul de Minas (SM), Alto São Francisco (ASF), Zona da Mata (ZM) e Zona Metalúrgica (MT)

\begin{tabular}{ccc}
\hline \multirow{2}{*}{ Região } & \multicolumn{2}{c}{ Gordura } \\
\cline { 2 - 3 } & Mozarela & M. padrão \\
\hline ASF & $0,71 \mathrm{aA}$ & $0,88 \mathrm{aA}$ \\
MT & $0,75 \mathrm{aA}$ & $0,76 \mathrm{aA}$ \\
ZM & $0,54 \mathrm{aB}$ & $0,61 \mathrm{aB}$ \\
SM & $1,06 \mathrm{aA}$ & $0,49 \mathrm{aA}$ \\
\hline
\end{tabular}

*Na linha, médias com letras maiúsculas distintas diferem entre si pelo teste Duncan $(\mathrm{P}<0,05)$

*Na coluna, médias com letras minúsculas distintas diferem entre si pelo teste Duncan $(\mathrm{P}<0,05)$

Os valores encontrados para a porcentagem de proteína no soro, média geral de $0,81+0,06 \mathrm{~g} / 100 \mathrm{~g}$ e $\mathrm{CV}=5,2 \%$, foram 
semelhantes aos relatados por vários autores (Furtado e Pombo, 1979; Chiappini e Santos, 1995; Kosikowski e Mistry, 1997), e o coeficiente de variação verificado por Siqueira (2000) foi mais alto que o observado neste experimento. Os valores para o teor de proteína no soro de queijo minas-padrão foram de 0,71 a $0,9 \mathrm{~g} / 100 \mathrm{~g}$ (média de $0,8 \mathrm{~g} / 100 \mathrm{~g}$ e $\mathrm{CV}=4,9 \%$ ) e no soro de queijo mozarela de 0,77 a $0,95 \mathrm{~g} / 100 \mathrm{~g}$ (média de $0,84 \mathrm{~g} / 100 \mathrm{~g}$ e $\mathrm{CV}=4,7 \%$ ), enquanto os encontrados por Siqueira (2000) foram de $1,43 \pm 0,54 \mathrm{~g} / 100 \mathrm{ml}$ (com resultados entre $0,87 \mathrm{e}$ $2,55 \mathrm{~g} / 100 \mathrm{ml})$ e $1,28 \pm 0,45 \mathrm{~g} / 100 \mathrm{ml} \quad(\mathrm{com}$ resultados entre 0,7 e $1,66 \mathrm{~g} / 100 \mathrm{ml}$ ) para soro de queijos minas-padrão e mozarela, respectivamente, com coeficientes de variação em torno de 36\%. Uma explicação para tal variação pode ser atribuída às metodologias empregadas nas análises (método de Kjehldal no presente experimento e método de Pyne em Siqueira, 2000). Houve interação soro $x$ região $(\mathrm{P}<0,01)$, sendo que o soro de minas-padrão exerceu maior influência nessa variação. A diferença entre os soros manifestou-se na interação, principalmente com as regiões Sul de Minas e Zona da Mata. A região Metalúrgica destacou-se por apresentar as maiores médias em ambos os soros (Tab. 7). O provável motivo de interação já foi discutido anteriormente e se aplica neste caso também.

Tabela 7. Teores de proteína $(\mathrm{g} / 100 \mathrm{~g})$ de soros de queijos mozarela e minas-padrão, das macrorregiões do Sul de Minas (SM), Alto São Francisco (ASF), Zona da Mata (ZM) e Zona Metalúrgica (MT)

\begin{tabular}{ccc}
\hline \multirow{2}{*}{ Região } & \multicolumn{2}{c}{ Proteínas } \\
\cline { 2 - 3 } & Mozarela & M. padrão \\
\hline ASF & $0,79 \mathrm{aA}$ & $0,81 \mathrm{aBC}$ \\
MT & $0,86 \mathrm{aA}$ & $0,88 \mathrm{aA}$ \\
ZM & $0,83 \mathrm{aA}$ & $0,77 \mathrm{bBC}$ \\
SM & $0,85 \mathrm{aA}$ & $0,73 \mathrm{bC}$ \\
\hline
\end{tabular}

*Na linha, médias com letras maiúsculas distintas diferem entre si pelo teste SNK $(\mathrm{P}<0,01)$

*Na coluna, médias com letras minúsculas distintas diferem entre si pelo teste SNK $(\mathrm{P}<0,01)$

Para os teores de cloreto de sódio presente no soro de queijo, a média geral foi de $0,19 \pm 0,02 \mathrm{~g} / 100 \mathrm{~g}$ e $\mathrm{CV}=7,7 \%$. Para soro de queijo minas-padrão, a média foi de $0,19 \pm 0,011$ (CV de 5,7\%); e para soro de queijo mozarela, foi de $0,18 \pm 0,015 \mathrm{~g} / 100 \mathrm{~g}$ (CV de $8,1 \%)$. Os teores de cloreto de sódio pesquisados foram diferentes dos encontrados por Siqueira (2000), $0,73+0,21 \quad(\mathrm{CV}=29,1)$ para soro de queijo Minas-padrão e 0,95+0,41 $(\mathrm{CV}=43,5)$ para soro de queijo mozarela, apesar de ter sido empregado o mesmo método em ambas as pesquisas. A principal diferença entre esses resultados é o fato de que se adicionava sal à massa do queijo que originava os soros, aumentando, assim, o teor de cloreto no soro, no caso do experimento de Siqueira (2000). Neste estudo, em todos os laticínios, a salga foi em salmoura, ou seja, após a extração e coleta do soro. Houve diferença significativa na interação soro $\mathrm{x}$ região. Apenas na região Metalúrgica o soro de queijo mozarela apresentou menor teor de cloreto de sódio quando comparado ao soro de minas-padrão (Tab. 8).

Tabela 8. Teores cloreto de sódio $(\mathrm{g} / 100 \mathrm{~g})$ de soros de queijos mozarela e minas-padrão, das macrorregiões do Sul de Minas (SM), Alto São Francisco (ASF), Zona da Mata (ZM) e Zona Metalúrgica (MT)

\begin{tabular}{ccc}
\hline \multirow{2}{*}{ Região } & \multicolumn{2}{c}{ Cloreto de sódio } \\
\cline { 2 - 3 } & Mozarela & M. padrão \\
\hline ASF & $0,19 \mathrm{aAB}$ & $0,19 \mathrm{aB}$ \\
MT & $0,17 \mathrm{bB}$ & $0,22 \mathrm{aA}$ \\
ZM & $0,21 \mathrm{aAB}$ & $0,19 \mathrm{aB}$ \\
$\mathrm{SM}$ & $0,18 \mathrm{aB}$ & $0,18 \mathrm{aB}$ \\
\hline
\end{tabular}

*Na linha, médias com letras maiúsculas distintas diferem entre si pelo teste SNK $(\mathrm{P}<0,01)$.

*Na coluna, médias com letras minúsculas distintas diferem entre si pelo tese SNK $(\mathrm{P}<0,01)$.

Os valores da densidade apresentaram média de $1,0252 \pm 0,0011$ e $\mathrm{CV}$ de $0,08 \%$. Para o soro de queijo minas-padrão, os valores variaram de 1,0230 a 1,0260 e, para soro de queijo mozarela, a variação foi de 1,0240 a 1,0270. Os resultados encontrados foram semelhantes aos de Furtado e Pombo (1979), Sbampato et al. (1998) e Siqueira (2000), que variaram entre 1,0246 e 1,0274. Observou-se diferença entre regiões, sendo a região Zona da Mata diferente das regiões do Sul de Minas e Metalúrgica, e estas duas diferentes entre si (Tab. 9).

Os valores de resíduo mineral fixo (cinzas) e de lactose das amostras de soro não foram diferentes entre regiões ou entre soros, apresentando, respectivamente, médias (e CV) de $0,48 \mathrm{~g} / 100 \mathrm{~g}(6,9 \%)$ e $4,27 \mathrm{~g} / 100 \mathrm{~g}(12,3 \%)$. Esses valores foram próximos aos citados por outros autores (Furtado e Pombo, 1979; Chiappini e 
Santos, 1995; Maciel et al., 1999), que estavam entre $4,80 \mathrm{~g} / 100 \mathrm{~g}$ a $5,64 \mathrm{~g} / 100 \mathrm{~g}$ para lactose e $0,39 \mathrm{~g} / 100 \mathrm{~g}$ e $0,65 \mathrm{~g} / 100 \mathrm{~g}$ para cinzas. Os valores de lactose encontrados por Siqueira (2000) variaram entre $2,04 \mathrm{~g} / 100 \mathrm{~g}$ e $4,17 \mathrm{~g} / 100 \mathrm{~g}$ para minas-padrão e entre $0,07 \mathrm{~g} / 100 \mathrm{~g}$ a $3,47 \mathrm{~g} / 100 \mathrm{~g}$ para mozarela. Esses valores são discrepantes em relação aos deste estudo, pois aproximadamente $80 \%$ da lactose do leite serão eliminados com o soro (Kosikowski e Mistry, 1997), o que poderia indicar que tal metodologia não seria apropriada para a análise nos testes realizados por Siqueira (2000).

Tabela 9. Densidade relativa de soros de queijos mozarela e minas-padrão, das macrorregiões do Sul de Minas (SM), Alto São Francisco (ASF), Zona da Mata (ZM) e Zona Metalúrgica (MT)

\begin{tabular}{cc}
\hline Região & Densidade relativa média \\
\hline MT & $1,0261 \mathrm{a}$ \\
ASF & $1,0255 \mathrm{ab}$ \\
SM & $1,0250 \mathrm{~b}$ \\
ZM & $1,0242 \mathrm{c}$ \\
\hline
\end{tabular}

*Letras diferentes indicam valores estatisticamente diferentes $(\mathrm{P}<0,05)$.

\section{CONCLUSÕES}

A baixa variação físico-química entre as amostras coletadas facilita a estipulação de padrões da composição do soro, o que viabiliza a inspeção do soro de queijo. As diferenças encontradas entre as regiões e a interação tipo de soro $\mathrm{x}$ região podem ser atribuídas à maior ou menor uniformidade do processamento, observada e registrada durante a coleta das amostras.

\section{REFERÊNCIAS BIBLIOGRÁFICAS}

BYLUND, G. Tratamento e utilização do soro. Rev. Inst. Lat. Cândido Tostes, v.30, p.29-43, 1975.

CAMARGO, D.S.; ALVES, G.; GARCIA, S. et al. Bebida fermentada à base de soro de leite e isolado protéico de soja. Semina, v.21, p.45-51, 2000.

CHIAPPINI, C.C.J.; FRANCO, R.M.; OLIVEIRA, L.A.T. Avaliação do soro de queijo quanto as bactérias heterotróficas aeróbias mesófilas e psicrófilas viáveis. Rev. Inst. Lat. Cândido Tostes, v.50, p.245-248, 1995.
CHIAPPINI, C.C.J.; SANTOS, N.N. Determinação de alguns parâmetros físicos e químicos do soro de queijo. Rev. Inst. Lat. Cândido Tostes, v.50, p.249-252, 1995.

COTON, S.G. Whey resources and utilization. J. Soc. Dairy Technol., v.38, p.97-100, 1985.

DETERMINATION of the nitrogen content. Inter. Dairy Fed. Standard, N. 20B, 1993. (IDF20B:1993)

DETERMINATION of total solids content. Inter. Dairy Fed. Standard, N. 21B, 1987. (IDF21B:1987)

DUARTE, M.; MÍDIO, A.F. Soro lácteo: características nutricionais e riscos na sua utilização. Hig. Alim., v.11, p.23-26, 1997.

EUCLIDES, R.F. Sistema para análises estatísticas - SAEG, versão 7.0, 2001. Disponível: <www.ufv.br/saeg/index.htm> Acessado em: $28 \mathrm{dez} 2003$.

FERREIRA, C.L.L.F. Relevância da utilização de soro e leitelho na indústria de laticínios. Ind. Lat., n. 11, p.39-40, 1997.

FONSECA, L.M. Fractionation of whey proteins by complex formation and membrane filtration. 1999. 250f. Tese (Doutorado) - University of Wisconsin, Madison.

FURTADO, M.M.; LOURENÇO NETO, J.P.M. Tecnologia de queijos: manual técnico para a produção industrial de queijos. São Paulo: Dipemar, 1994. p.76-77.

FURTADO, M.M.; POMBO, A.F.W. Fabricação de queijo prato e minas: estudo do rendimento. Rev. Inst. Lat. Cândido Tostes, v.34, p.3-19, 1979.

JARDIM, L. O sucesso do leite brasileiro. Rev. Veja. 2004. Disponível em: $<$ htpp//veja.abril.com.br/081204/radar.html $>$. Acessado: em 12 jan. 2005.

JAY, J.M. Microbiologia moderna de los alimentos. 3.ed. Zaragoza: Acribia, 1993. 804p.

KOSIKOWSKI, F.V.; MISTRY, V.V. Cheese and fermented milk foods. 3.ed. Westport: FV Kosikowski, LLC, 1997. v.1 e 2.

KOSKOWSKI, F.V. Whey utilization and whey products. J. Dairy Sci., v.62, p.1149-1160, 1979. 
MACIEL, J.F.; SANTOS, J.V.P.; SARAIVA, S.H, et. al. Enriquecimento nutricional de pão de forma com soro de queijo. Rev. Inst. Lat. Cândido Tostes. v.54, p.114-116, 1999.

MARTINS, E. Patrimônio de Minas. Jornal Estado de Minas, dez, 2001. p.14-17. (Caderno Economia, n. 44).

MARWAHA, S.S.; KENNEDY, J.F. Review: whey-pollution problem and potential utilization. Int. J. Food Sci. Technol., n.23, p.323-336, 1988.

MÉTODOS analíticos oficiais para controle de produtos de origem animal e seus ingredientes: II. Métodos físicos e químicos. Brasília: Ministério da Agricultura, 2003.

MINAS Gerais registra superávit na balança comercial de lácteos. 2005. Disponível em: $<$ www.laticinio.net/noticias $>$. Acessado em: 12 jan. 2005.

MORR, C.V. Effect of heating and elevated temperature storage on cheese whey. J Food Sci., v.55, p.1177-1179, 1990.

OFFICIAL methods of analysis. 16.ed. Washington: AOAC, 1995. v.2. 1094p.

SBAMPATO, C.G.; ABREU, L.R.; FURTADO, M.M. et al. Influencia de dois sistemas de pasteurização na composição do leite e do soro do queijo tipo gorgonzola. Rev. Inst. Lat. Cândido Tostes, v.53, p.15-22, 1998.

SAMPAIO, I.B.M. Estatística aplicada à experimentação animal. Belo Horizonte: Fundação de Ensino e Pesquisa em Medicina Veterinária e Zootecnia, 2002. 221p.

SIQUEIRA, I.M.C. Avaliação da Qualidade físico-química e microbiológica de quatro tipos de soro de queijo. 2000. 104f. Dissertação (Mestrado) - Faculdade de Farmácia, Universidade Federal de Minas Gerais, Belo Horizonte, MG.

SPILOTRO, D. Queijos de grife. Rev. Dial. Med., n.4, p.30-33. 2003.

TEIXEIRA, L.V.; FONSECA, L.M.; MENEZES, L.D.M. Avaliação da qualidade do soro de queijos minas padrão e mozarela produzidos em quatro regiões do estado de Minas Gerais. Arq. Bras. Med. Vet. Zootec., v.59, p.264-267, 2007.

WOLFSCHON, A.F.; FURTADO, M.M. Composição média dos soros de queijo prato e minas. Rev. Inst. Lat. Cândido Tostes, v.32, p.2123, 1977. 